Results There was co-occurrence between adversities, and particularly for retrospectively reported adversities. Three latent classes were identified in the prospective data - 'Low ACEs', 'Household dysfunction' (2.8\%) and 'Parental loss' $(1.5 \%)$ which were related to increased inflammation in mid-life, as were high cumulative risk scores and individual measures of offending, death, divorce, physical neglect and family conflict. Four latent classes were identified in the retrospective data - 'Low ACEs', 'Parental mental health and substance misuse', 'Maltreatment and conflict' and 'Polyadversity.' The latter two (5.2\%) were related to raised inflammation in mid-life, as was a retrospective ACE score of $4+(8.3 \%)$ and individual measures of family conflict, psychological and physical abuse, emotional neglect and witnessing abuse.

Discussion Specific ACEs or ACE combinations might be important for chronic inflammation. LCA is an alternative approach to operationalising ACEs data but further research is needed. Identifying the specific ACEs or combinations of ACEs which are most strongly related to inflammation is important for investigating the mechanisms involved and the planning of effective interventions.

\section{OP48 IS STATE SCHOOL EDUCATION REALLY FREE? LISTENING TO CHILDREN'S VIEWS ON THE COSTS OF THE SCHOOL DAY}

${ }^{1} \mathrm{~L}$ Naven*, ${ }^{2} \mathrm{E}$ Sosu, ${ }^{3} \mathrm{~S}$ Spencer, ${ }^{1} \mathrm{~J}$ Egan. ${ }^{1}$ Glasgow Centre for Population Health, Glasgow, UK; ${ }^{2}$ School of Education, University of Strathclyde, Glasgow, UK; ${ }^{3}$ Child Poverty Action Group, Glasgow, UK

\subsection{6/jech-2020-SSMabstracts.48}

Background In the context of child poverty and educational attainment in Scotland, the Cost of the School Day (CoSD) project privileged children's voices to examine the potential influence of school policies and practices on the ability of children from low-income families to participate fully in the school day.

Methods A purposive sample of Glasgow schools (4 primaries and 2 secondaries) was chosen, to ensure representation across the socio-economic spectrum using the Scottish Index of Multiple Deprivation. Pupils over 16 years could opt in to focus group sessions, and consent was sought from parents/carers of pupils under 16. Sessions used a vignette of a fictional character from a low-income household, allowing a safe degree of personal distance for pupils to explore sensitive topics. Groups, comprising pupils of mixed gender and free school meal entitlement, took part in two sessions. Initial sessions identified costs involved in attending school, and follow-up sessions considered potential actions needed by schools. 71 focus group sessions with 282 pupils were carried out. Deductive thematic analysis was carried out using QSR NVivo software.

Results Pupils identified substantial barriers to participation in the school day and suggested potential solutions. Key themes centered around transport costs, access to afterschool activities and fun events, curriculum costs for subjects and textbooks, home schoolwork resources and school uniform costs.

Pupils highlighted that transport costs present barriers to holiday revision classes and after-school clubs and activities, and suggested providing clubs and supported study at different times of the school day to ensure transport is not an issue.

Curriculum costs for subjects, textbooks and specimen papers were raised, as well as internet and computing requirements for homework. Groups felt that schools should offer more than one way of completing homework.

School uniform emerged as a major cost leading to stigma and embarrassment, absence, or exclusions for non-compliance. Pupils felt more support is needed to ensure affordability, schools should signpost to the cheapest uniform suppliers, and systems are needed to avoid pupils feeling embarrassed.

Conclusion The findings support the argument that the way the curriculum is structured and implemented is more advantageous to pupils from higher-income households. The CoSD tapped into the Scottish Government policy cycle and resulted in changes to increase the school clothing grant across Scotland, and, at Glasgow level, to automate clothing grant payments to ensure uptake. The CoSD lessons are transferrable across education systems and are being further rolled out in 128 schools across the UK.

\section{OP49 PERCEPTIONS OF ADOLESCENT HEALTH RISK BEHAVIOUR AND SOCIOECONOMIC POSITION: A GROUNDED THEORY STUDY OF YOUNG ADULTS IN BRISTOL}

L Tinner*, D Caldwell, M Hickman, R Campbell. Population Health Sciences, Bristol Medical School, University of Bristol, Bristol, UK

\subsection{6/jech-2020-SSMabstracts.49}

Background Health risk behaviours such as tobacco smoking, alcohol consumption, drug misuse, unhealthy diet and unprotected sexual intercourse are global health issues, often initiated in adolescence. There is contrasting evidence on the association between health risk behaviours and socioeconomic position in adolescence and young adulthood, with little qualitative evidence to illuminate the relationship. The aim of the study was to examine to what extent young people perceive health risk behaviours to shape socioeconomic inequalities while transitioning into adulthood.

Methods We undertook a nested qualitative study within The Avon Longitudinal Study of Parents and Children (ALSPAC) birth cohort using semi-structured interviews of 25 young adults aged 26-28 years. A grounded theory approach was adopted. Theoretical sampling was conducted based on participants' early life socioeconomic background and engagement in health risk behaviours when they were adolescents. Data collection and analysis were undertaken iteratively to aid constant comparison.

Results Categories of peer influence, family influence, 'drive to succeed' and personal responsibility were identified. These data underline the importance of family and peers in relation to both health risk behaviours and socioeconomic life chances as young people transition into adulthood. Engaging in some level of health risk behaviour allowed young people to gain experiences and bond with peers but avoiding certain behaviours helped construct their identity and self-security. Some participants adopted a moralistic or neoliberal perspective in labelling peers who engaged in certain risk behaviours, such as drug use, as irresponsible or immature. Adolescent alcohol use was seen as normative 